\title{
Railroad Track Condition Monitoring Using Inertial Sensors and Digital Signal Processing: A Review
}

\author{
Leonard Chia, Bhavana Bhardwaj, Pan Lu*, Raj Bridgelall
}

\begin{abstract}
Inertial sensors such as accelerometers and gyroscopes have been widely used since the early 1990s to monitor the condition of transportation assets. Recent improvements in their performance, a reduction in cost, and sensor miniaturization has resulted in a growing interest expanding their use. This research is an extensive and systematic review of their application considerations, challenges, and opportunities for improvements in railroad track condition monitoring. Research questions were developed to guide the selection of relevant articles from databases. The authors report key findings in the areas of sensor specification, sensor location, and sensor signal processing.
\end{abstract}

Index Terms - Digital signal filtering, Sample rate, Sensors, Track geometry monitoring

\section{INTRODUCTION}

A $\mathrm{N}$ inertial sensor is an electronic device designed to measure orientation with gyroscopes and accelerations with accelerometers. Inertial sensors are widely used in transportation infrastructure inspection and condition monitoring. Some studies such as Velaga et al and Zhang et al [1], [2] describe how the information from global positioning systems (GPS) can be fused with inertial sensors to generate the vehicle trajectory to enhance the map-matching in vehicle navigation system. Another study by Stocker et al [3] uses vibration (accelerometer) sensors to monitor pavement acceleration and magnetometer sensors for vehicle detection. However, the use of inertial sensors for monitoring railroad infrastructure is limited. For the railroad industry, the process of monitoring is to identify faults, understand their causes, and to predict their occurrence by identifying and characterizing track irregularities. Track inspection, on the other hand, mainly focuses on using measurement technologies such as a track recording vehicle (TRV) or hauling a track recording coach (TRC) around to accumulate data on the track geometry. The scope of this paper focuses on the use of inertial sensors to monitor transportation infrastructures, especially railroad tracks to identify faults.

The railroad industry has a significant impact on the nation's economy and energy consumption. Track condition monitoring is fundamental and critical for ensuring the safety, reliability,

"This work was partially supported by the U.S. Department of Transportation under agreement NO. DTRT13-G-UTC38 through Mountain Plains Consortium Transportation Center No. MPC-505 Project FAR0025914 and NDSU development Project No. FAR0021386."

L. Chia, B. Bhardwaj, P. Lu*, and R. Bridgelall are with the Department of and cost-efficiency of railroad operations [4]. Federal track safety regulation require railroads to inspect all tracks in operation as often as twice weekly. Railroad companies deploy expensive and relatively slow methods using human inspectors and expensive automated inspection vehicles to inspect and monitor their rail tracks. The current practice is expensive and also decreases the rail productivity by reducing track time for railroad industry to perform inspection which also increases the safety risk for railway inspection workers.

Sensors such as inertial sensor, accelerometers, gyroscopic sensors, and global position system (GPS), are carried on a railway vehicle to continuously monitor and inspect rail assets to meet the growing needs of safety improvement, reliable and low-cost rail operations. Therefore, this research reviews the current literature to understand the challenges and opportunities for further research to optimize and reduce the cost of the application.

This paper presents a review of the application of inertial sensors to track condition monitoring. The review focuses on developments from the early 90 s to the present time. The paper covers the proof of concept on track condition monitoring using inertial sensing during the early stages, the development, the evolution, and the application over the past decade, and future research directions.

\section{METHODS}

A set of research questions guided the literature review and subsequently focused the selection of articles for detailed review.

\section{A. Research Questions}

The following research questions focused the literature review on methods and considerations in railroad track condition monitoring using inertial sensors:

1) What existing applications use inertial sensors to identify track issues?

2) What types of track faults were identifiable?

3) What types of inertial sensors were used?

4) What are the sensor data processing algorithms?

5) Where are the sensor installed and how are their locations determined?

Transportation and Logistics, North Dakota State University, ND 58108 USA. * Corresponding author: Pan.lu@ndsu.edu 


\section{6) What are the challenges that researchers face?}

\section{B. Article Selection}

The authors systematically searched published peerreviewed journal articles and papers found in the Web of Science: Core Collection (Thomas Reuters), ProQuest SciTech Collection, Engineering Village (Elsevier), Transport Research International Documentation (TRID) and IEEE Xplore from January 1, 1990 to April 30, 2017. Coverage and relevance in engineering and transportation were the important factors in selecting these five electronic databases. The searched keyword string was "("inertial sensor" OR accelerometer OR gyroscope OR IMU) AND (track OR rail OR railroad) AND ("health monitoring" OR condition)" for the title, abstract, and keyword fields of their search engines.

The initial total number of articles identified was 4,654. The first selection stage involved a review of the title and abstract of each article. After excluding unrelated and duplicated articles, the number of relevant articles reduced to 40 . The second selection stage involved a careful review of these 40 articles, obtained from North Dakota State University Library. The criteria for including an article in the final literature review were: (1) the study involved inertial sensors, and (2) the study reported on track fault detection, track condition monitoring, fault estimation, or fault location.

\section{FINDINGS}

This section organizes and summarizes the findings from the literature review in terms of the key considerations and the technical challenges of using inertial sensors to monitor the condition of railroad tracks. The key considerations are to determine the sensor specifications, the sensor locations, and the design of the signal processing methods.

\section{A. Sensor Specification}

Many varieties of inertial sensors are available on the market, ranging from uniaxial accelerometer/gyroscopes to inertial measurement units (IMUs) with 6 degrees of freedom. The dynamic range of the measurements varied, depending on the sensor type and implementation characteristics. For accelerometers the dynamic range was from $\pm 2 \mathrm{~g}$ to $\pm 500 \mathrm{~g}$, where $\mathrm{g}$ is the $\mathrm{g}$-force unit. For gyroscopes, the dynamic range of the measurements was from $\pm 50^{\circ} \mathrm{s}-1$ to $1,000^{\circ} \mathrm{s}-1$.

The inertial sensors were all sampled at different rates, and the signal filtered within different frequency ranges, depending on the purpose of the study and the system design. Inertial sensors and their configurations varied, depending on the purpose of the study. Table 1 summarizes the specifications and sensors used in these studies. The articles reported no clear indication of the sensor selection, and most did not report on the sensor types, their configurations, or the rationale for their selection. In general, the selection of sensor type (accelerometer and/or gyroscope) was independent on the faults or track irregularities analyzed. For example, a direct integration based approach required measurements of both acceleration and angular velocity. In some cases, the selection of sensor dynamic range of measurement was determined by the location of the sensor. In most cases, a more remotely attached sensor had a larger measurement dynamic range.

\section{B. Sensor Attachment Location}

Most of the reviewed studies subjectively chose to attach the inertial sensors to the axle-box or the bogie. One study by Bocciolone et al [12] attempted to collect data from inside the cabin on an overhead luggage rack. A study by Wei et al [34] attached the sensors to the floor of the train and processed signals to identify faults in terms of track geometry irregularities. Six studies [7], [8], [13], [16], [29], [31] attached inertial sensors to the car body to identify track geometry irregularities. Table 1 summarizes the sensor characteristics and their attachment locations.

None of the reviewed articles reported on the effect of the sensor attachment locations on the quality of signal measurements and the selection of signal processing algorithms. However, some studies found that the following factors need to be considered while selecting a sensor location:

(1) The linkage between sensor measurement and the train speed. Even traveling at the same speed, the characteristics of acceleration and angular velocity are different from location to location. Therefore, the performance of fault detection algorithms depend on the sensor location [23].

(2) The vibration of the wheel to rail contact and the suspension system. Vibration and other noise introduced during sensor data collection may corrupt the measured signals and result in false positives or missed detections [18], [20], [24]. In particular, one study by Wei et al [34] found that it was difficult to detect low frequency car body vibrations using threshold processing methods.

Most of the reviewed studies focused on using inertial sensors to detect certain types of rail defects (Table 2). In general, the literature review provided evidence that researchers have successfully applied inertial sensors to identify track geometry issues. Almost all of the applications focused on either vertical track defects or rail corrugation. The exception is one study that focused on squat and thermite weld detection. Sensor locations were subjective, and they varied even for the same type of fault identification. Therefore, the authors identify considerations for sensor placement as a gap in the literature [23]. One study by Li et al used a fault classification method with fault identification and isolation systems to identify the fault type and level [37]. That application included signal filtering techniques, which is discussed further in the next section.

\section{Signal Filtering Techniques}

Signals from inertial sensors contain noise and other unwanted signal elements, including low-frequency components such as undesirable offsets. Therefore, the selection of the appropriate signal filtering technique is crucial to the success of the application. Signal filtering reduces or eliminates unwanted signal features or enhances the desirable features in some frequency ranges that could help to identify faults [38].

\section{Track Fault Identification}

To understand the basics of the filter, it is essential to comprehend how the information is contained in the signals. There are two domains that contain information of interest: 
- Time domain where the phase and amplitude of a signal contains information.

- Frequency domain where the spectral content of the signal contains information [39].

Complete information about the filter can be represented by an impulse response, a step response, and a frequency response. All three responses describe how the filter will react in different circumstances [40]. However, filters are most easily understood by either their step responses or their frequency responses [39].

In the time domain, the impulse response is the output sequence when the input is an impulse preceded and followed by zero-valued samples [41]. Frequency response is obtainable by calculating the discrete Fourier transform (DFT) of the impulse response [42].

The step response is the filter's output given an abrupt change in the input signal. It is also used to measure how well a filter performs in the time domain. The following three parameters that are necessary to evaluate the performance of the filter: rise time, overshoot, and phase linearity [39], [40].

- $\quad$ Rise Time - the number of output samples between $10 \%$ and $90 \%$ of the output change.

- Overshoot - a filter generated distortion of the information contained in the time domain which appears as ripples at the edges of the output steps.

- $\quad$ Phase Linearity - the symmetry of the step response above and below the 50\% amplitude threshold.

In the frequency domain, the purpose of the filters is to allow some frequency (pass band) to pass unaltered, while completely blocking other frequencies (stop band). The frequencies between the boundaries of the pass band and stop band are within the transition band, which occurs around the filter's cutoff frequency.

- Pass band - the range of frequencies over which a filter passes signal energy.

- Stop band - the range of frequencies from which the filter removes signal energy.

- Transition - the range of frequencies between the passband and the stopband.

- Cut off frequency - a frequency located at the halfpower level between the pass band and the stop band.

In the frequency domain, three parameters, namely the roll-off, passband ripple, and stopband attenuation characterizes the performance of four common type of filters: low-pass, highpass, band-pass, and band-reject.

- Roll off - describes the steepness of the filter response in the transition region from the passband to the stopband.

- $\quad$ Passband ripple - a distortion of signals occurring in the passband.

- Stopband attenuation - the amount by which the filter lessens the range of frequencies that the filter blocks.

\section{1) Type of Filters}

High pass, low pass, band pass, or band reject filters are implemented as either analog or digital filters. A popular implementation of digital filters is the linear time invariant filter (LTI). Analog filters use analog electronic circuits, made up of resistors, capacitors, and operational amplifier, to produce the required filtering effect. These filters are widely used in applications such as noise reduction, graphic equalizers in hi-fi systems, and many other areas.

Digital filters are a vital part of digital signal processing and have two general purposes: signal separation and signal restoration [40]. Various digital filters are based on the fast Fourier transform, which is a mathematical algorithm that quickly extracts the frequency spectrum of a signal, thus allowing the spectrum to be manipulated before conversion into the equivalent time-series signal. There are two categories of digital filters - recursive or non-recursive.

Signal separation is required when a signal has been contaminated with interference, noise, or other unwanted signals. Signal restoration is used when a signal has been distorted in some way. Advantages of digital filters [43] are that:

- They can be adaptive by using an algorithm and a programmable processor to adjust the frequency response automatically.

- Thermal and environmental variations cannot change their performance.

- They can handle low-frequency signals accurately.

- They can be changed easily without affecting the circuitry.

- Fast DSP processors can manage a complex combination of filters in parallel or in series

The disadvantages of digital filters [43] are that:

- They require a much longer time to design and build

- The achievable signal bandwidth is much lower than that of the analog counterpart.

Common frequency domain filters operate as:

- Low-pass -- passes energy at low frequencies and attenuates energy at high frequencies.

- High-pass -- passes energy at high frequencies and attenuates energy at low frequencies.

- $\quad$ Band-pass -- passes energy in one frequency band and attenuates energy above and below that band.

- Band-reject -- passes energies in frequencies other than those in a particular range.

The selection of frequency domain filters depends on the research targets and application needs. Moreover, some common advantages and disadvantages of frequency domain filters are often important selection criteria. The advantages of frequency domain filters are:

- Frequency filtering is more efficient when using convolution with large kernels

- The reverse process of deconvolution is similarly efficient

- $\quad$ Filters have a low cost and are easy to control

The disadvantages of frequency domain filters are:

- The filter is only a first-order filter and the transition band containing the cutoff frequency may not be sufficiently steep to achieve the desired results.

\section{2) Implementation of Digital Filters}

Linear time invariant filters (LTI) are those whose behavior does not change over time. They are described in terms of difference equations. Linearity means that the filter meets the following scaling and superposition properties:

$\mathrm{X}[\mathrm{n}] \rightarrow \mathrm{y}[\mathrm{n}]=>\alpha \mathrm{x} 1[\mathrm{n}]+\beta \mathrm{x} 2[\mathrm{n}] \rightarrow \alpha \mathrm{y} 1[\mathrm{n}]+\beta \mathrm{y} 2[\mathrm{n}]$ 
LTI filters are implemented using finite impulse response (FIR) or infinite impulse response (IIR) methods. The general representation of the FIR filter of length $\mathrm{N}$ is:

$y[n]=\sum_{k=0}^{M} b_{k} x[n-k]$

where $x[n]$ is the input signal, $y[n]$ is the output signal, $M$ is the filter order (order $\mathrm{M}=\mathrm{N}-1$ ), bk is the value of the impulse response at the $\mathrm{kth}$ instant for $0 \leq \mathrm{k} \leq \mathrm{M}$. Characteristics of an FIR filter is as follows [44]:

- The output is based on weighted delays of the input signal

- It is entirely a discrete time domain method

- It is a feedforward filter

- Its implementation is non-recursive or transversal

- It has only zeros (no poles), also known as all-zero filters.

- Its advantage are that it is: always stable, prevents phase distortion (linear phase), offers great flexibility in shaping their magnitude response

- Its drawbacks are that it: requires more computation than IIR filters with a similar effect and requires more memory

The basic structure of the FIR filter requires a multiplier, an addition, and a unit delay. The general representation of the IIR filter is:

$$
y[n]=\sum_{l=1}^{N} a_{l} y[n-l]+\sum_{k=0}^{M} b_{k} x[n-k]
$$

where $b_{k}$ are the feed-forward coefficients, $a_{1}$ is the feedback coefficients. To implement such a system, computing each output signal value requires $\mathrm{N}+\mathrm{M}+1$ multiplies. However, the system is of $\mathrm{N}^{\text {th }}$ order since the number of poles has a significant influence on the system properties. Characteristics of IIR filters are as follows [45]:

- based on transforming a continuous-time analog filter into discrete-time filter

- incorporates delays of the output signal

- $\quad$ allow both zeros and poles

- $\quad$ cn be implemented with recursion

- $\quad$ is a feedback filter

- advantages include: leverages decades of experience in designing analog filter; less expensive than FIR filters; allows for greater shaping potential

- drawbacks include: can have phase distortion and ringing; are not guaranteed to be stable

Kalman filter: A Kalman filter (KF) is a model based method. A Kalman filter offers more practical implementations based on the recursive concept [37]. A KF consists of a predictive block and correction block. Time update uses the dynamic equation to predict the next time step. Measurement update explains how the information available in the new measurement is incorporated into the estimate. The time update of the KF consists of the current state prediction and system process covariance calculation [37]. The current state prediction is:

$X_{k}=A X_{k-1}+B U_{k}$

and the covariance calculation is:

$$
P_{k}=A P_{k-1} A^{T}+Q
$$

where $\mathrm{U}_{\mathrm{k}}$ is the input of the system. $\mathrm{A}$ and $\mathrm{B}$ are the system matrices of the linearized vehicle model, $X_{k}$ is an a priori state estimate at step $\mathrm{k}$ given knowledge of the process prior to step $\mathrm{k}, X_{k-1}$ is an a posterior state estimate at step $\mathrm{k}-1$, and $\mathrm{Q}$ is the covariance of the system process.

The measurement update consists of Kalman gain, state update, and covariance update. The Kalman gain is:

$K_{k}=P_{k} H^{T}\left(H P_{k} H^{T}+R\right)^{-1}$

and the state update is

$\hat{X}_{k}=X_{k}+K_{k}\left(Z_{k}-H X_{k}\right)$.

The covariance update is

$\hat{P}_{k}=\left(I-K_{k} H\right) P_{k}$

where $K_{k}$ is the Kalman gain, $\widehat{\mathrm{X}}_{\mathrm{k}}$ is the predicted result at time step $\mathrm{k}, \mathrm{R}$ is the covariance of the measurment noise $\mathrm{V}_{\mathrm{k}}$ and $\mathrm{I}$ is the identity matrix of 1 . The KF is widely used for linear systems and can offer an effective and efficient estimation for them. However, it cannot provide accurate estimation for nonlinear systems. Rather, the Extended Kalman filter is used for nonlinear system estimation, but it has some constraints [37]:

- Sufficiently small time steps for stability

- Sufficiently small time step intervals inevitably increase the analysis time.

Convolution is the mathematical process of combining two signals to form a third signal that has much better performance than those created by recursion filters, but execute much more slowly [40]. They are also called finite impulse response filters. However, use of these filters creates a delay so that all incoming samples receive the same treatment, this preserving the signal phase relationship [39]. An algorithm called FFT convolution is used to increase the speed of the convolution, which allows the FIR filter to perform faster.

In DSP, an impulse is a signal composed of all zeros except a single non-zero point. Here, three important terms are used: delta function $(\delta[n])$, which is a normalized impulse frequently called the unit impulse. An impulse response $(h[n])$ is the output of a linear system when the input is a delta function. The input and output signals are often represented as $\mathrm{x}[\mathrm{n}]$ and $\mathrm{y}[\mathrm{y}]$.

If the input to a system is an impulse, which can be expressed as a shifted (integer quantity) and scaled delta function, i.e. $\mathrm{x}(\mathrm{k})$ $\square \delta[\mathrm{n}-\mathrm{k}]$, where $\mathrm{k}$ is the sample index number (coefficient), an input signal $\mathrm{x}[\mathrm{n}]$ enters a linear system with an impulse response $\mathrm{h}[\mathrm{n}]$, resulting in an output signal $\mathrm{y}[\mathrm{n}]$. In the equation form:

$$
Y[n]=x[n] * h[n]
$$

where the * symbol represents the convolution operation. The convolution sum is a general expression of a filter's output in terms of the impulse response such that

$$
y_{(n)}=\sum_{k=0}^{M} h[k] x[n-k] \text {. }
$$

Deconvolution is a filtering implementation that reverses the process of convolution. Recreating the signal as it existed before the convolution took place. Deconvolution works well in the frequency domain. It usually requires knowing the characteristic of the convolution, which is the impulse response and the output vector (spectra). Researchers [40], [46] have applied deconvolution filtering to measure railcar body vertical accelerations. The authors used Laplace transform theory and 
pole-zero plots to achieve the deconvolution. In essence, deconvolution filtering eliminates or at least reduces the amplification and attenuation effects of the railcar suspension system. The advantages of deconvolution filtering are that they are often linear, deterministic, non-iterative and fast. The disadvantages are their sensitivity to noise, which can result in noise amplification and the difficulty of incorporating available a priori information

\section{3) Track Fault Identification}

Model-based methodologies are preferred when there is no direct measurement of parameters but the relationship between the input signals and output signals are known. The evaluation of residuals of the model-based methodologies can identify faults or irregularities in the dynamic systems. Inputs for the model are the sensor collected data, which are then used to predict the dynamic behavior of the vehicle system. A comparison of the model outputs with the real-time measured output produces residuals. Minimizing of the residuals by adjusting the model parameters could yield an estimation of the faults/irregularities in tracks.

The Kalman filter is widely used as an effective health monitoring method for linear systems and the extended Kalman filter is normally used for nonlinear stochastic systems. The Kalman filter is widely used for state and parameter estimation.

In [47], a 2-axle railway vehicle with solid axle wheelsets was studied using a KF-based state observer. The researchers used three accelerometers and five gyroscopes to estimate the vehicle dynamics and track information that are related to the 18 state variables from the sensors. The estimation errors of low-frequency components increase dramatically with the increase in accuracy of estimation due to the reduction of sensor noises.

The extended Kalman filter was used in a fault detection and isolation system for a secondary and anti-yaw dampers of a Coradia Class 175 railway vehicle [48], [49]. Only lateral motion and yaw motion of two wheelsets and one bogie and lateral motion of the car body is considered when developing a half train model of the vehicle. A limitation of Kalman filter is that is only able to deal with white noise, so the dynamic equations of this model are extended with a sharper filter to cover the later track irregularities. Fault detection and isolation are calculated using the residual of measurements and estimation with extended Kalman filtering. Simulation results using the extended Kalman filter are found to be acceptable.

Signal-based methods are developed for use when the output signal is the only signal available. Such methods analyze the output signals directly by extracting fault related characteristics in various ways. Once extracted from noise, the amplitudes or amplitude densities within a certain bandwidth of a signal could be indications of the fault relevant signal characteristics. Changes in the frequency and amplitudes can be analyzed to estimate the parameters from the parametric signal models. The signal processing methods used are spectral analysis, wavelet analysis and band-pass filters [50].

Spectral analysis is widely used to acquire more intuitive fault-relevant features than time-domain analysis [51]. However, the performance of spectral methods will depend heavily on the selection of the signal window size. In another study [52], two different approaches were used to detect faults in the suspension of a Shinkansen vehicle. In the first approach, "healthy" and "unhealthy" parts are used for suspension fault detection using the peak distribution of acceleration signals. In the second approach, "healthy" and "unhealthy" vehicles with faults in one bogie were compared using the vibration states. Based on the ideal fault-relevant frequencies, faults can be detected. Sensor-collected data were analyzed using a band pass filter. Differences in vibration state distribution are taken as fault indicators.

\section{CONCLUSION AND CHALLENGES}

This paper presents an overview of the existing techniques used for inertial sensors on-board railway vehicles for railroad track condition monitoring. Model-based and signal based methods are both discussed, including a presentation of the basic theories, applications, and analysis.

\section{A. Inertial Sensor Application}

The application of inertial sensors is being introduced on railway vehicles for track condition monitoring. Inertial sensors deliver robust performance, and are readily available at a low cost, with low power consumption, and are small in size. The displacement information of the vehicle can be acquired based on the acceleration signals from inertial sensors but there is still a need to improve their accuracy. Inertial sensors can be attached or mounted at various parts of the vehicle such as the axle boxes, bogies, car-bodies or the overhead luggage rack. Due to the high-magnitude impact forces of wheel-rail interaction, the life cycle of sensors that are mounted on axle boxes or any other position below the suspension system is limited. Moreover, the effects of sensor location on signal data quality and fault identification accuracy needs further research.

Previous research show that the application of inertial sensors was successfully used on railway vehicles going over known track faults and after the digital signal processing of the inertial data, can identify several track faults such as vertical track defects, rail corrugation, track alignment, vertical rail profile, squat and thermite weld, track irregularity and track geometry. Even so, their locations varied for the same fault target. Previous research shows that sensor positioning decisions are subjective. Further research is needed on methods of objective decision-making for positioning the sensor.

One challenge for sensor monitoring analysis is to identify the right measurements. Reliable and valid measurements are important for an effective condition monitoring approach. There is the question of finding relevant and correct parameters in order to obtain the most relevant measuring data. Subsequently, a transformation of that data into relevant and understandable information will help decision-makers in the maintenance management process.

\section{B. Challenges of Filter Practices}

The sample rate of the inertial sensors may vary during operating because of slight variations in processing speed and sensor data acquisition between samples. That is, in practice, sensors do not sample at exactly the rate requested. Furthermore, different sensor platforms or embedded systems may sample at different rates, despite identical settings. Subsequently, different sensor platforms will capture inertial 
energy from various frequency bands at the higher end of the spectrum.

Filters in electronic systems have cutoff frequencies that applies to an edge in a low-pass, high-pass, band-pass or bandreject characteristic - a frequency characterizing a boundary between a passband and a stopband. A cutoff frequency is determined by the $-3 \mathrm{~dB}$ point of a filter magnitude response relative to a peak passband value. Digital filtering at a fixed cutoff frequency will normalize the sampled signals from different sensors or different sensor platforms and remove unwanted or noisy components.

Aliasing is an effect that causes different signals to become indistinguishable when sampled. In other words, highfrequency input signals will appear as low-frequency signals at the output. If aliasing occurs, no signal processing operation downstream of the sampling process can recover the original continuous time signal. Aliasing occurs when a signal is sampled too slowly. To prevent aliasing, the signal must be sampled at least twice as fast as the highest frequency component (Nyquist criterion). Also, aliasing is avoided by applying an anti-aliasing filter (a low-pass filter) with a cut-off frequency of $f \_s 2$. This filter removes frequencies greater than $\mathrm{f} \_\mathrm{s} 2$ where $\overline{\mathrm{f}} \mathrm{s}$ is the sampling frequency. The Nyquist sampling theorem dictates that the maximum cutoff frequency of a digital filter must be less than half the minimum sample rate of the sensor.

Group delay distortion occurs when signals at different frequencies take a different amount of time to pass through a filter. If the phase response is linear, the group delay of the filter is constant, which means that each frequency component experiences the same delay. Otherwise, the frequency components have different delays, which causes a smearing phenomenon in the time-domain signal. It is important to describe a filter's passband characteristics or evaluate the filter's phase nonlinearity.

In practice, due to tradeoffs in roll-off steepness, filter delay and computational complexity, the maximum cutoff frequency should be set much lower than half the minimum sample rate of the sensor. Therefore, some practices use as high a sample rate as possible, within some reasonable considerations for minimizing the data accumulation rate and the sensor power consumption.

Inertial sensors suffer from bias instability, noisy output, and insufficient resolution. Digital filtering is an important technique used to address such issues. Many studies have been conducted or proposed to obtain "good" digital filters that have high performance. However, in practical applications, few research results are used efficiently. Because the research field of digital filters has become diverse and complicated, there is a lack of understanding of what constitutes a good digital filter and how to obtain it.

\section{Future Research}

In future work, the authors will address these gaps in the literature in terms of system design, implementation, and evaluation. The effort will include an analysis to optimize the number and positions of sensors, develop methods of appropriate digital signal filtering, develop techniques of signal feature extraction, and study their linkages to track fault identification.

\section{ACKNOWLEDGMENT}

A grant from the United States Department of Transportation supported this research under Grant DTRT13-G-UTC38.

\section{REFERENCES}

[1] N. R. Velaga, M. A. Quddus, and A. L. Bristow, "Improving the Performance of a Topological Map-Matching Algorithm Through Error Detection and Correction," J. Intell. Transp. Syst., vol. 16, no. 3, pp. 147-158, 2012.

[2] T. Zhang, D. Yang, J. Li, and X. Lian, "A TrajectoryBased Map-Matching System for the Driving Road Identification in Vehicle Navigation Systems," J. Intell. Transp. Syst., vol. 20, no. 2, pp. 162-177, 2016.

[3] M. Stocker, P. Silvonen, M. Rönkkö, and M. Kolehmainen, "Detection and Classification of Vehicles by Measurement of Road-Pavement Vibration and by Means of Supervised Machine Learning," J. Intell. Transp. Syst., vol. 20, no. 2, pp. 125-137, 2016.

[4] F. Beeck, "TRACK CIRCUIT MONITORING TOOL Standardization and Deployment at CTA," No. Transit IDEA Project 83. December, 2017.

[5] Y. Naganuma, W. Suzuki, K. Itaya, T. Kohama, and S. Nakamura, "A complete digital inertial measurement system for railway track geometry," WIT Trans. Built Environ., vol. 50, 2000.

[6] P. Weston, P. Li, C. Ling, C. Goodman, R. Goodall, and C. Roberts, "Track and vehicle condition monitoring during normal operation using reduced sensor sets," HKIE Trans., vol. 13, no. 1, pp. 47-54, 2006.

[7] T. Kojima, H. Tsunashima, and A. Matsumoto, "Fault Detection of Railway Track by Multi-Resolution Analysis," in Computers in Railways $X$. The Tenth International ConferenceWessex Institute of Technology, 2006.

[8] Y. Hayashi, T. Kojima, H. Tsunashima, and Y. Marumo, "Real Time Fault Detection of Railway Vehicles and Tracks," in Railway Condition Monitoring, 2006. The Institution of Engineering and Technology International Conference on, 2006, pp. 20-25.

[9] P. Weston, C. Roberts, C. Goodman, and C. Ling, "Condition Monitoring of Railway Track using In-Service Trains," in Railway Condition Monitoring, 2006. The Institution of Engineering and Technology International Conference on, 2006, pp. 26-31.

[10] P. Weston, C. Ling, C. Goodman, C. Roberts, P. Li, and R. Goodall, "Monitoring lateral track irregularity from inservice railway vehicles," Proc. Inst. Mech. Eng. Part F J. Rail Rapid Transit, vol. 221, no. 1, pp. 89-100, 2007.

[11] P. F. Weston, C. S. Ling, C. Roberts, C. J. Goodman, P. $\mathrm{Li}$, and R. M. Goodall, "Monitoring vertical track irregularity from in-service railway vehicles," Proc. Inst. Mech. Eng. Part F-J. Rail Rapid Transit, vol. 221, no. 1, pp. 75-88, 2007.

[12] M. Bocciolone, A. Caprioli, A. Cigada, and A. Collina, "A measurement system for quick rail inspection and effective track maintenance strategy," Mech. Syst. Signal Process., vol. 21, no. 3, pp. 1242-1254, 2007.

[13] H. Mori, H. Tsunashima, T. Kojima, A. Matsumoto, and T. Mizuma, "Condition Monitoring of Railway Track Using In- 
service Vehicle," J. Mech. Syst. Transp. Logist., vol. 3, no. 1, pp. $154-165,2010$.

[14] T. Uhl, K. Mendrok, and A. Chudzikiewicz, "Rail track and rail vehicle intelligent monitoring system," Arch. Transp., vol. 22, no. 4, p. 495, 2010.

[15] M. Molodova, Z. Li, and R. Dollevoet, "Axle box acceleration: Measurement and simulation for detection of short track defects," Wear, vol. 271, no. 1-2, pp. 349-356, 2011.

[16] H. Tsunashima, Y. Naganuma, A. Matsumoto, T. Mizuma, and H. Mori, "Japanese railway condition monitoring of tracks using in-service vehicle," in Railway Condition Monitoring and Non-Destructive Testing (RCM 2011), 5th IET Conference on, 2011, pp. 1-6.

[17] J. Lee, S. Choi, S. Kim, Y. Kim, S. Kim, and C. Park, "Track condition monitoring by in-service trains: A comparison between axle-box and bogie accelerometers," in Railway Condition Monitoring and Non-Destructive Testing (RCM 2011), 5th IET Conference on, 2011, pp. 1-6.

[18] O. Heirich, A. Lehner, P. Robertson, and T. Strang, "Measurement and analysis of train motion and railway track characteristics with inertial sensors," IEEE Conf. Intell. Transp. Syst. Proc. ITSC, pp. 1995-2000, 2011.

[19] A. M. Boronakhin et al., "MEMS-based inertial system for railway track diagnostics," Gyroscopy Navig., vol. 2, no. 4, pp. 261-268, 2011.

[20] J. Real, P. Salvador, L. Montalbán, and M. Bueno, "Determination of rail vertical profile through inertial methods," Proc. Inst. Mech. Eng. Part F J. Rail Rapid Transit, vol. 225, no. 1, pp. 14-23, 2011.

[21] J. S. Lee, S. Choi, S. S. Kim, C. Park, and Y. G. Kim, “A mixed filtering approach for track condition monitoring using accelerometers on the axle box and bogie," IEEE Trans. Instrum. Meas., vol. 61, no. 3, pp. 749-758, 2012.

[22] J. I. R. Herráiz, M. L. M. Domingo, T. Real, and V. Puig, "Development of a system to obtain vertical track geometry measuring axle-box accelerations from in-service trains," in Journal of Vibroengineering, 2012, vol. 14, pp. 813-826.

[23] M. Bagshawe, "Investigating inertial measurements using MEMS devices in trainborne automatic track condition monitoring applications," in Control and Automation 2013: Uniting Problems and Solutions, IET Conference on, 2013, pp. $1-6$.

[24] H. TSUNASHIMA and Y. SAITO, "Development of compact size onboard device for condition monitoring of railway tracks," J. Mech. Syst. Transp. Logist., vol. 6, no. 2, pp. 142-149, 2013.

[25] G. Yeo, P. Weston, and C. Roberts, "The utility of continual monitoring of track geometry from an in-service vehicle," 2014.

[26] V. Ákos, "Rolling Contact Fatigue on Tramway's Rail," in Proceedings of the International Conference on Road and Rail Infrastructure CETRA, 2014.

[27] H. Tanaka, A. Shimizu, and K. Sano, "Development and verification of monitoring tools for realizing effective maintenance of rail corrugation," in IET Conference Proceedings, 2014.

[28] H. Tsunashima, H. Mori, K. Yanagisawa, M. Ogino, and A. Asano, "Condition monitoring of railway tracks using compact size on-board monitoring device," in Railway
Condition Monitoring (RCM 2014), 6th IET Conference on, 2014, pp. 1-5.

[29] L. Qin, D. Wei, and Y. B. Sun, "Design of onboard device to diagnose track fault online," in Applied Mechanics and Materials, 2014, vol. 483, pp. 465-470.

[30] T. Real, J. M. Monje, M. L. M. Domingo, C. Zamorano, and J. I. R. Herráiz, "Design and validation of a railway inspection system to detect lateral track geometry defects based on axle-box accelerations registered from in-service trains," in Journal of Vibroengineering, 2014, vol. 16, pp. 234-248.

[31] X. Zhang, L. Jia, X. Wei, and N. Ru, "Railway track condition monitoring based on acceleration measurements," in Control and Decision Conference (CCDC), 2015 27th Chinese, 2015, pp. 923-928.

[32] S. Li, A. Núñez, Z. Li, and R. Dollevoet, "Automatic Detection of Corrugation: Preliminary Results in the Dutch Network Using Axle Box Acceleration Measurements," in 2015 Joint Rail Conference, 2015, p. V001T01A023V001T01A023.

[33] P. Salvador, V. Naranjo, R. Insa, and P. Teixeira, "Axlebox accelerations: Their acquisition and time-frequency characterisation for railway track monitoring purposes," Measurement, vol. 82, pp. 301-312, 2016.

[34] X. Wei, F. Liu, and L. Jia, "Urban rail track condition monitoring based on in-service vehicle acceleration measurements," Meas. J. Int. Meas. Confed., vol. 80, pp. 217228, 2016.

[35] H. Tanaka, M. Matsumoto, and Y. Harada, "Application of axle-box acceleration to track condition monitoring for rail corrugation management," in Railway Condition Monitoring 2016 (RCM 2016), 7th IET Conference on, 2016, pp. 1-7.

[36] G. Lederman, S. Chen, J. H. Garrett, J. Kovačević, H. Y. Noh, and J. Bielak, "Track monitoring from the dynamic response of a passing train: A sparse approach," Mech. Syst. Signal Process., vol. 90, pp. 141-153, 2017.

[37] C. Li, S. Luo, C. Cole, and M. Spiryagin, "An overview: modern techniques for railway vehicle on-board health monitoring systems," Veh. Syst. Dyn., vol. 55, no. 7, pp. 10451070, 2017.

[38] H. Munguia, “Tutorial Filtros,” 2017.

http://paginas.fisica.uson.mx/horacio.munguia/aula_virtual/Cu rsos/Instrumentacion\%20II/Documentos/Tutorial\%20Filtros.p df . Accessed on $3^{\text {rd }}$ Jan 2018

[39] R. Quinnell, "Designing Digital Filters | EE Times," EETimes, Aug-2003. [Online]. Available: http://www.eetimes.com/document.asp?doc_id=1275863.

[40] S.W. Smith and others, "The scientist and engineer's guide to digital signal processing," San Diego, CA, USA, California Technical Publication, 1997

[41]R. G. Lyons, Understanding Digital Signal Processing, 2 edition. Upper Saddle River, NJ: Prentice Hall, 2004.

[42] J. Picked, "EDN Access-- 4.27.95 Impulse-response testing lets a single test do the work of thousands," EDN, Apr1995. .

[43] A. Mahmud, "Digital Filter And Its Advantages and Disadvantages!," EzineArticles, 22-May-2012. [Online]. Available: http://ezinearticles.com/?Digital-Filter-And-ItsAdvantages-and-Disadvantages!\&id=7076035. 
[44] E. Punskaya, "Design of FIR Filters," Mater. Adapt. Courses Prof Simon Godsill Dr Armout Doucet Dr Malcolm Macleod Prof Peter Rayner, 2010.

[45] J. Fessler, "IIR Filters.".

http://www.eecs.umich.edu/courses/eecs206/archive/f02/publi c/lec/136.pdf . Accessed on $3^{\text {rd }}$ Jan 2018

[46] L. Al-Nazer and others, "Track profile approximation using railcar body acceleration data.," United States. Federal Railroad Administration. Office of Research and Development, 2014.

[47] T. Mei, R. Goodall, and H. Li, "Kalman filter for the state estimation of a 2-axle railway vehicle," in Control Conference (ECC), 1999 European, 1999, pp. 2431-2435.

[48] P. Li, R. Goodall, P. Weston, C. Seng Ling, C. Goodman, and C. Roberts, "Estimation of railway vehicle suspension parameters for condition monitoring," Control Eng. Pract., vol. 15, no. 1, pp. 43-55, 2007.

[49] P. Li and R. Goodall, "Model-based condition monitoring for railway vehicle systems," Control 2004, 2004.

[50] S. Bruni, R. Goodall, T. Mei, and H. Tsunashima, "Control and monitoring for railway vehicle dynamics," Veh. Syst. Dyn., vol. 45, no. 7-8, pp. 743-779, 2007.

[51] K. Fong, A. P. Loh, and W. W. Tan, "A frequency domain approach for fault detection," Int. J. Control, vol. 81, no. 2, pp. 264-276, 2008.

[52] T. Oba, K. Yamada, N. Okada, and K. Tanifuji, "Condition monitoring for Shinkansen bogies based on vibration analysis," J. Mech. Syst. Transp. Logist., vol. 2, no. 2, pp. 133-144, 2009. 


\section{TABLE I Inertial Sensor Specifications in Reviewed Studies}

\begin{tabular}{|c|c|c|c|c|c|c|c|c|c|}
\hline \multirow[t]{3}{*}{ Source } & \multirow[t]{3}{*}{ Year } & \multirow{3}{*}{$\begin{array}{l}\text { Sensor } \\
\text { Model }\end{array}$} & \multirow{3}{*}{$\begin{array}{l}\text { Number } \\
\text { of } \\
\text { Sensors }\end{array}$} & \multicolumn{4}{|c|}{ Types and Specification } & \multirow{3}{*}{$\begin{array}{c}\text { Sampling } \\
\text { Frequency } \\
\text { (Hz) }\end{array}$} & \multirow{3}{*}{$\begin{array}{l}\text { Position of } \\
\text { the Sensor }\end{array}$} \\
\hline & & & & \multicolumn{2}{|c|}{ Accelerometer } & \multicolumn{2}{|c|}{ Gyroscope } & & \\
\hline & & & & $\begin{array}{c}\text { Measuring } \\
\text { Axes }\end{array}$ & $\begin{array}{c}\text { Measuring } \\
\text { Range }\end{array}$ & $\begin{array}{c}\text { Measuring } \\
\text { Axes }\end{array}$ & $\begin{array}{c}\text { Measuring } \\
\text { Range }\end{array}$ & & \\
\hline $\begin{array}{l}\text { Naganuma } \\
\text { et al [5] }\end{array}$ & 2000 & & 4 & 2 & & 3 & & & Axle-box \\
\hline $\begin{array}{l}\text { Weston et } \\
\text { al [6] }\end{array}$ & 2006 & & 15 & 3 & $\begin{array}{l} \pm 100 \mathrm{~g} ; \pm 10 \\
\pm 4 \mathrm{~g}\end{array}$ & 3 & & 4000 & Bogie frame \\
\hline $\begin{array}{l}\text { Kojima et } \\
\text { al [7] }\end{array}$ & 2006 & & 3 & 3 & & & & 2000 & $\begin{array}{l}\text { Vehicle } \\
\text { body, axle- } \\
\text { box }\end{array}$ \\
\hline $\begin{array}{l}\text { Hayashi et } \\
\text { al [8] }\end{array}$ & 2006 & & 3 & 3 & & & & 2000 & $\begin{array}{l}\text { Vehicle } \\
\text { body and } \\
\text { axle-box }\end{array}$ \\
\hline $\begin{array}{l}\text { Weston et } \\
\text { al [9] }\end{array}$ & 2006 & & & 3 & & 3 & & & $\begin{array}{l}\text { Bogie, axle- } \\
\text { box }\end{array}$ \\
\hline $\begin{array}{l}\text { Weston et } \\
\text { al [10] }\end{array}$ & 2007 & & 4 & 2 & & 3 & & & Bogie \\
\hline $\begin{array}{l}\text { Weston et } \\
\text { al [11] }\end{array}$ & 2007 & & 4 & 2 & $\pm 10 \mathrm{~g}$ & 3 & $\pm 50^{\circ} \mathrm{s}^{-1}$ & & Bogie \\
\hline $\begin{array}{l}\text { Bocciolone } \\
\text { et al [12] }\end{array}$ & 2007 & & 9 & & $\pm 250 \mathrm{~g}$ & & & 3000 & $\begin{array}{l}\text { Each axle- } \\
\text { box of } \\
\text { bogie }\end{array}$ \\
\hline $\begin{array}{l}\text { Tsunashima } \\
\text { et al [13] }\end{array}$ & 2010 & & 3 & 3 & & 3 & & 2000 & $\begin{array}{l}\text { Car body } \\
\text { and bogie }\end{array}$ \\
\hline $\begin{array}{l}\text { Uhl et al } \\
{[14]}\end{array}$ & 2010 & & 3 & 3 & & & & & $\begin{array}{l}\text { Bearing box } \\
\text { of wheelset }\end{array}$ \\
\hline $\begin{array}{l}\text { Molodova } \\
\text { et al [15] }\end{array}$ & 2011 & & & 3 & & & & & Axle-box \\
\hline $\begin{array}{l}\text { Tsunashima } \\
\text { et al [16] }\end{array}$ & 2011 & & 3 & 3 & & 3 & & & Car body \\
\hline $\begin{array}{l}\text { Lee et al } \\
{[17]}\end{array}$ & 2011 & & & 3 & & 3 & & 2048 & $\begin{array}{l}\text { Axle-box } \\
\text { and bogie }\end{array}$ \\
\hline $\begin{array}{l}\text { Heirich et } \\
\text { al [18] }\end{array}$ & 2011 & XsensMTx & 1 & 3 & & & & 100 & $\begin{array}{l}\text { Overhead } \\
\text { luggage } \\
\text { rack }\end{array}$ \\
\hline $\begin{array}{l}\text { Boronakhin } \\
\text { et al [19] }\end{array}$ & 2011 & & 4 & 3 & & 3 & & 4000 & Axle boxes \\
\hline $\begin{array}{l}\text { Real et al } \\
{[20]}\end{array}$ & 2011 & & 5 & 3 & & & & & $\begin{array}{l}\text { Axle-box, } \\
\text { bogie }\end{array}$ \\
\hline $\begin{array}{l}\text { Lee et al } \\
{[21]}\end{array}$ & 2012 & & 2 & & & & & 2048 & $\begin{array}{l}\text { Axle-box } \\
\text { and bogie }\end{array}$ \\
\hline $\begin{array}{l}\text { Herráiz et } \\
\text { al [22] }\end{array}$ & 2012 & $\begin{array}{c}\mathrm{PCB} \\
354 \mathrm{C} 02\end{array}$ & 4 & 3 & $\pm 500 \mathrm{~g}$ & & & 100 & $\begin{array}{l}\text { Lead bogie } \\
\text { axle-box }\end{array}$ \\
\hline $\begin{array}{l}\text { Bagshawe } \\
{[23]}\end{array}$ & 2013 & & 2 & 3 & $\pm 3 g$ & & & & Bogie \\
\hline $\begin{array}{l}\text { Tsunashima } \\
\text { and Saito } \\
{[24]}\end{array}$ & 2013 & & 3 & 3 & & 3 & & 1000 & On board \\
\hline $\begin{array}{l}\text { Yeo et al } \\
{[25]}\end{array}$ & 2014 & & 3 & 3 & & 3 & & & Bogie \\
\hline Ákos [26] & 2014 & & 2 & 3 & & & & & $\begin{array}{l}\text { Driving } \\
\text { wheels; free } \\
\text { running } \\
\text { wheels }\end{array}$ \\
\hline
\end{tabular}




\begin{tabular}{|c|c|c|c|c|c|c|c|c|}
\hline $\begin{array}{l}\text { Tanaka et } \\
\text { al [27] }\end{array}$ & 2014 & & 3 & 3 & & 3 & & On-board \\
\hline $\begin{array}{l}\text { Tsunashima } \\
\text { et al [28] }\end{array}$ & 2014 & & 2 & 3 & & 3 & 82 & On-board \\
\hline $\begin{array}{l}\text { Qin et al } \\
\text { [29] }\end{array}$ & 2014 & $\begin{array}{c}\text { acc: } \\
\text { ADIS16223; } \\
\text { ADIS16240; } \\
\text { ADIS16003 }\end{array}$ & 3 & $3 ; 3 ; 2$ & $\begin{array}{c} \pm 70 \mathrm{~g} \\
\pm 18 \mathrm{~g} ; \pm 1.7 \mathrm{~g}\end{array}$ & & $\begin{array}{c}79,200 \\
4000 \\
10,000\end{array}$ & $\begin{array}{l}\text { Axle-box; } \\
\text { bogie; car- } \\
\text { body }\end{array}$ \\
\hline $\begin{array}{l}\text { Real et al } \\
{[30]}\end{array}$ & 2014 & $\begin{array}{c}\text { acc: PCB } \\
354 \mathrm{C} 02\end{array}$ & 4 & 3 & & & & $\begin{array}{l}\text { Lead bogie } \\
\text { axle-boxes }\end{array}$ \\
\hline $\begin{array}{l}\text { Zhang et al } \\
\text { [31] }\end{array}$ & 2015 & & 4 & 3 & & & 2000 & Car body \\
\hline Li et al [32] & 2015 & & & 3 & & & & $\begin{array}{l}\text { Wheel axles } \\
\text { boxes }\end{array}$ \\
\hline $\begin{array}{l}\text { Salvador et } \\
\text { al [33] }\end{array}$ & 2016 & $\begin{array}{c}\text { acc: } \\
\text { KS76C100 }\end{array}$ & 2 & 3 & $\pm 60 \mathrm{~g}$ & & & $\begin{array}{l}\text { Motor } \\
\text { bogie, } \\
\text { trailer bogie }\end{array}$ \\
\hline $\begin{array}{l}\text { Wei et al } \\
{[34]}\end{array}$ & 2016 & & 8 & 3 & $2 \mathrm{~g}, 10 \mathrm{~g}$ & & 2000 & $\begin{array}{l}\text { Car body } \\
\text { floor, bogie } \\
\text { frame }\end{array}$ \\
\hline $\begin{array}{l}\text { Tanaka et } \\
\text { al [35] }\end{array}$ & 2016 & & 4 & 3 & $\pm 50 \mathrm{~g}$ & & 2000 & $\begin{array}{l}\text { Axle-box of } \\
\text { bogie }\end{array}$ \\
\hline $\begin{array}{l}\text { Lederman } \\
\text { et al [36] }\end{array}$ & 2017 & $\begin{array}{c}\text { acc: } \\
\text { vibrametric } \\
\text { model 5102; } \\
\text { PCB } \\
354 \mathrm{C} 02\end{array}$ & 5 & 2,3 & & & 1,600 & $\begin{array}{l}\text { Wheel } \\
\text { truck; inside } \\
\text { cabin }\end{array}$ \\
\hline
\end{tabular}




\section{TABLE II Targeted Fault and Location of Sensors in Reviewed Studies}

\begin{tabular}{|c|c|c|c|}
\hline $\begin{array}{l}\text { Research } \\
\text { Year }\end{array}$ & Target Fault & Sensor Type and Method & Location of Sensors \\
\hline 2000 & Vertical track defects & Accelerometer & Railcar axle \\
\hline 2006 & Rail corrugation & Accelerometer & Axle box and car body \\
\hline 2006 & Rail corrugation & Accelerometer & Car body \\
\hline 2007 & Rail corrugation & Accelerometer & Bogies \\
\hline 2007 & Track alignment & Accelerometer/gyroscope & Bogie \\
\hline 2010 & Vertical track defects & Accelerometer/gyroscope & Bogie \\
\hline 2011 & Vertical and lateral track defects & Accelerometer & Car body \\
\hline 2011 & Vertical rail profile & Accelerometer & Railcar axle \\
\hline 2011 & Squat and thermite weld & Accelerometer & Axle box \\
\hline 2011 & $\begin{array}{l}\text { Orientation and Basic Track } \\
\text { Geometry }\end{array}$ & Accelerometer/gyroscope & Car body \\
\hline 2011 & Vertical defects and level & Accelerometer/gyroscope & Axle box \\
\hline 2012 & Vertical defects and alignment & Accelerometer & Bogie \\
\hline 2012 & Track irregularity & Accelerometer & Axle box and bogie \\
\hline 2013 & Vertical track defects & Accelerometer/gyroscope & Car body \\
\hline 2013 & Track irregularity & Accelerometer/gyroscope & Car body \\
\hline 2014 & Lateral Alignment & Accelerometer & Axle box \\
\hline 2014 & Track Geometry & Accelerometer & Car body \\
\hline 2014 & Rail corrugation & Accelerometer/gyroscope & Car body \\
\hline 2016 & Track alignment and track geometry & Accelerometer & Car body and bogie \\
\hline
\end{tabular}

